\section{Informal prerequisites for informal proofs}

\author{
Aiso Heinze, Jee Yi Kwak, \\ Oldenburg (Germany)
}

\begin{abstract}
Reasoning and proof play an important role in the mathematics classroom. However, prerequisites for the learning of mathematical reasoning and proof, such as logical competence or the understanding of concepts and proofs, are rarely taught explicitly. In an empirical survey with 106 students in grade 8 we investigated students' declarative and methodological knowledge related to some of these prerequisites. The results show that there are certain deficits which make it difficult for students to learn reasoning and proof.
\end{abstract}

Kurzreferat: Beweisen und Begründen sind wichtige Ziele des Mathematikunterrichts. Das Erlernen von mathematischem Beweisen und Begründen setzt dabei bestimmte Fähigkeiten und Kentnisse voraus, wie beispielsweise logische Kompetenz, Begriffs- und Beweisverständnis, die im Mathematikunterricht allerdings häufig nicht explizit behandelt werden. Die Ergebnisse einer empirischen Untersuchung von 106 Schülerinnen und Schülern aus Jahrgang 8 zeigen, dass diese Voraussetzungen für das Erlernen von Beweisen und Begründen nur unzureichend gegeben sind.

\section{ZDM-Classification: C30, C40, G20, G40, E50}

In school mathematics, proof is one of the main methods for developing deductive reasoning ability and promoting the understanding of mathematics. The beginning of teaching and learning of mathematical argumentation and proof is often linked to the geometry classroom in grade 7 or 8. Despite these facts, geometry and, in particular, argumentation and reasoning in the geometry classroom is often regarded by teachers as a less important topic. In contrast, mathematicians and mathematics educators consider geometry as an important part of mathematics education (Lehrer \& Chazan, 1998).

\section{Theoretical framework}

\subsection{Proof and argumentation in mathematics classroom}

Logical argumentation, reasoning and proving are important aims of the mathematics classroom. These skills are the basis for the development of the mathematical science and, moreover, they are important qualifications which are indispensable for the education in a modern society. Consequently, the National Council of Teachers of Mathematics (NCTM) recently declared reasoning and proof to one of the ten standards in the NCTM Principles and Standards (NCTM, 2000). The NCTM pointed out: "Mathematical reasoning and proof offer powerful ways of developing and codifying insights about a wide range of phenomena. People who reason and think analytically explore the properties and structure of objects and systems. They note patterns and regularities in both realworld and symbolic objects; they ask if those patterns are accidental or if things have to be that way; and they conjecture and prove. Ultimately, a mathematical proof represents the formal codification of patterns of reasoning and justification (NCTM, 2000)."

In recent years many researchers in mathematics education and cognition psychology contributed to the description and explanation of proving processes and their prerequisites. There is a wide range of investigations starting from empirical investigations in the students' proof ability (e.g., Senk 1985; Healy \& Hoyles, 1998; Reiss, Klieme \& Heinze, 2001), to the development of theoretical models of the proving process (Balacheff, 1988; Boero, 1999), philosophical background about proving in mathematics and mathematics classroom (Hanna, 1983; Hanna \& Jahnke, 1996; Hanna, 1997) and the identification of individual proof schemes (Harel \& Sowder, 1998). Furthermore, in the Third International Mathematics and Science Study (TIMSS) (Beaton et. al, 1996; Baumert, Bos \& Lehmann, 2000) argumentation and proof played a role in several items.

The empirical investigations show that the students' abilities in mathematical reasoning and proof are rather poor. In particular, the investigation of Healy and Hoyles with 2500 high-attaining tenth grade students in Great Britain shows that even these students have great difficulties in generating proofs. The students were far from proficient in constructing mathematical proofs and were more likely to rely on empirical verification. However, they were frequently able to recognise a correct proof. The empirical findings of Reiss, Klieme \& Heinze (2001) in their investigation of reasoning and proof abilities of upper secondary students correspond to the results of Healy and Hoyles, though in upper secondary level more students know that empirical argumentation is not allowed in a mathematical proof. The results of TIMSS Germany indicate that the student performance in mathematics for many students in grade 7 or 8 is not sufficient for a deeper understanding of mathematical concepts and procedures in higher grades (Baumert, Bos \& Lehmann, 2000).

\subsection{Geometrical competence and prerequisites for proof in the geometry classroom}

As described above, the performance of students of the lower and upper secondary level in reasoning and proof in the mathematics classroom is comparatively low. To find the reasons for this fact, particularly in the case of the geometry classroom, researchers in the field of mathematics education and cognition psychology tried to identify aspects of geometrical competence which are prerequisites for the students' abilities in reasoning and proof in geometry. Recent research has focused on the cognitive processes and specific knowledge structures needed to solve geometrical (proof-)problems. Empirical results based on work with questionnaires, observing and interviewing students and think-aloud protocols show that the declarative knowledge, i.e., the knowledge on geometrical axioms, definitions and theorems is necessary but not sufficient to be successful in solving geometrical proof-problems. Greeno (1980) describes three types of geometrical knowledge: (a) theorems and rules, (b) visual patterns - like the image of corresponding angles - and (c) 
"strategic principles" which, for example, govern the construction of proofs. By Koedinger \& Anderson (1990) mathematicians do not construct proofs by retrieving definitions and theorems from their memory and putting these together to logical deductions. On the contrary, they do not pay attention to each detail in the proving process but consider the line of argumentation in broad terms and recognise important properties and connections. Consequently, Koedinger (1998) stated that for the geometrical competence specific skills play an important role in addition to the declarative knowledge. Reiss, Klieme \& Heinze (2001) identified certain aspects of geometrical competence in their investigation with students in the upper secondary school. Based on empirical data, they found that high level geometry competence is specifically influenced by spatial ability, declarative knowledge, metacognition and methodological knowledge (e.g., knowledge of the principles of mathematical proofs). First results of an investigation with more than 600 high-attaining students in grade 7/8 confirm that declarative knowledge, metacognition and methodological knowledge are also prerequisites for the geometrical competence in the lower secondary level (Reiss \& Hellmich, submitted). The fact that spatial ability as a component of general intelligence is of importance for geometrical competence was already stated by Clemens \& Battista (1992).

\subsection{Research questions}

According to recent results in the identification of prerequisites for the students' abilities of reasoning and proving in geometry, we investigated different aspects of the declarative and methodological knowledge of students. In this empirical survey, we focused on students which are at the beginning of learning mathematical reasoning and proofs. In contrast to the other above mentioned surveys, we were not concerned with high-attaining students but with students in grade 8 in the German Realschule. In general, the teaching and learning of mathematical argumentation, reasoning and proof starts in grade 7 or grade 8 in Germany. The high-attaining students in the German Gymnasium (grades 7 - 13) starts in grade 7 with proofs of simple geometrical statements. For the students in the German Realschule (grades 7 - 10) proofs frequently appear for the first time in geometry in grade 8 and, in general, the students in the German Hauptschule (grades 7 - 9) will stay on the level of argumentation.

The investigation of the students' declarative and methodological knowledge was operationalized in five general mathematical concepts and principles which, from our point of view, are important aspects as prerequisites for performing proof problems in geometry. Moreover, these five mathematical concepts and principles are rarely taught or discussed explicitly in the mathematics classroom.

The research questions corresponding to the declarative knowledge are the following:

- Are students able to give definitions of geometrical objects?

- Are they able to identify equivalent descriptions of a geometrical object?
The knowledge of correct definitions and alternative descriptions of the properties of geometrical objects is regarded as necessary for the construction of geometrical reasoning and proofs (e.g., Moore, 1994). Empirical findings in this area show that the ideas of students about a geometrical object and a mathematical definition of this object are frequently inconsistent (e.g., Hershkowitz \& Vinner, 1980; Hershkowitz \& Vinner, 1982; Wilson, 1990). The use of examples as an interpretation of definitions is often restricted to certain prototypes, which in addition contain irrelevant characteristics. Distinguishing between these irrelevant characteristic properties and the relevant definitional properties is difficult for students (Burger \& Shaughnessy 1985; Burger \& Shaughnessy, 1986; Wilson, 1986). To describe the difference between students' ideas of a geometrical object and its mathematical definition Vinner introduced the notion of the concept image. The concept image can be described as the personal definition of a concept which an individual has in his mind (Vinner, 1991). Other student problems related to definitions are the students' understanding of necessary and sufficient conditions in definitions and their imprecise use of words if they give definitions (Burger \& Shaughnessy, 1985; Burger \& Shaughnessy, 1986; Wilson, 1990). In our study, we were also interested in the question whether students prefer a description of a geometrical object, i.e., if they define a geometrical object by other objects, or if they prefer a drawing.

On the field of methodological knowledge, the research questions are the following:

- What kind of arguments convince students that a mathematical statement is true and do students recognise correct and false proofs?

- Do students know that, in general, the converse of a logical implication is not true?

- Are they familiar with the principle of counterexamples?

A correct understanding of a mathematical proof or mathematical reasoning is a necessary condition for the students' ability of constructing proofs. Research in the field of students' scientific thinking skills shows that there are several restriction in the preadolescent scientific thinking (Kuhn, 1989). According to Flavell (1977), an empirical-inductive reasoning is typical for students on the concrete-operational stage, whereas the hypotheticaldeductive reasoning is typical for the formal-operational stage. Empirical findings of investigations with grade 13, grade 10 and grade 8 students support this fact: the preference for empirical arguments in a mathematical proof is in grade 8 much higher than in grade 10 or grade 13 (de Villiers, 1992; Healy \& Hoyles, 1998; Reiss \& Thomas, 2000; Hoyles \& Küchemann, 2001; Reiss \& Hellmich, submitted).

One of the basic elements of deductive reasoning is the use of logical implications. As described above, students' ideas of geometrical objects are frequently inconsistent with mathematical definitions because of restricted student concepts of these objects. In this study, we are interested in the students' understanding of logical implications. One of the basic ideas here is the fact that, in general, the converse of logical implications is not true.

To understand the fact that a counterexample is suffi- 
cient for refuting a statement is part of a correct understanding of mathematical reasoning and proof. Restrictions in the scientific thinking make it difficult for grade 8 students to understand this fact. In general, students in lower and also in upper secondary level treat refutations of conjectures in various ways such as modifying conjectures, considering the counterexample as an exception and so on (Balacheff, 1991; Reiss \& Thomas, 2000). Using counterexamples requires a correct understanding of definitions, recognition of the inconsistency produced by the counterexample and deductive reasoning. All this combined together is difficult for students.

With the five concepts and principles (definitions, equivalent descriptions, arguments and proof, logical implication and counterexamples) we investigate important aspects of mathematical competence which, in particular, can be regarded as prerequisites for successful reasoning and proving skills in mathematics. These aspects are clearly not independent from each other since, for example, the usage of counterexamples requires a correct understanding of definitions.

\section{Design of the study}

In the present study the five mathematical concepts and principles were represented by ten items in a paper and pencil test. This test was administered by a teacher in four classes of grade 8 in a German Realschule. Altogether the sample comprised of 106 students (50 female, 53 male, no data 3 ). The students were asked to answer the test in 45 minutes.

For the two research questions related to the declarative knowledge (Are students able to give definitions? and Are they able to identify equivalent descriptions of a geometrical objects?), the students were asked to give definitions of the perpendicular bisector of a line and of an isosceles triangle. Furthermore, two simple geometrical objects (square and equilateral triangle) were considered and for each of these objects six different alternative descriptions were given. Here, the students had to mark the correct ones (multiple choice); in the first case, three descriptions were correct and, in the second case, four.

The three research questions related to the methodological knowledge were treated in different ways. To get ideas about the students' understanding of argumentation, reasoning and proof a proposition was selected which the students were supposed to know (the sum of the interior angles of a triangle is $180^{\circ}$ ) and the students were asked, why this statement is true. Moreover, we gave three different solutions for a proof of the statement about vertical angles - an empirical solution, a correct proof and the proof of a special case - and the students had to choose which of these solutions they prefer and which is correct. For the question about the converse of a logical implication we presented a statement and asked if the converse statement is also true. Here we chose a daily life situation ("If it rains, then the street becomes wet.") and a mathematical situation with simple geometrical objects ("If a quadrangle is a rectangle, then the opposite sides are parallel."). For the principle of counterexamples we asked the students to proof that two given conjectures are not true. These conjectures ("Each angle in a quadrangle is of $90^{\circ}$ " and "For any triangle resp. quadrangle we can draw a circle through the three resp. four points.") were presented as dialogs ("Klaus says ... Karin contradicts ... How can you show that Karin is right?").

\section{Results}

\subsection{Are students able to give definitions?}

For the first item corresponding to this question, we get the results in Table 1. We see that nearly the same number of students (14 resp. 15) gave the definition of a perpendicular bisector of a line as a description or as a drawing.

Table 1: Definition of a perpendicular bisector

\begin{tabular}{|l|c|c|}
\hline & Frequency & Percentage \\
\hline correct (description) & 14 & $13,2 \%$ \\
\hline correct (drawing) & 15 & $14,2 \%$ \\
\hline incomplete (description) & 8 & $7,5 \%$ \\
\hline incomplete (drawing) & 29 & $27,4 \%$ \\
\hline false & 18 & $17,0 \%$ \\
\hline no response & 22 & $20,8 \%$ \\
\hline
\end{tabular}

Altogether, only $27,4 \%$ of the students were able to give a correct definition. If we consider the incomplete definitions, then we observe that most of them are drawings $(27,4 \%$ to $7,5 \%)$. If we consider only the complete or incomplete solutions, i.e., the solutions of the students who know what the perpendicular bisector of a line is, then we can see that two thirds of them chose the drawing and only one third the description as a definition.

In the case of the isosceles triangle, we get different results (Table 2).

Table 2: Definition of an isosceles triangle

\begin{tabular}{|l|c|c|}
\hline & Frequency & Percentage \\
\hline correct (description) & 40 & $37,7 \%$ \\
\hline correct (drawing) & 3 & $2,8 \%$ \\
\hline special case (description) & 29 & $27,4 \%$ \\
\hline special case (drawing) & 3 & $2,8 \%$ \\
\hline incomplete (description) & 7 & $6,6 \%$ \\
\hline incomplete (drawing) & 12 & $11,3 \%$ \\
\hline false / no response & 12 & $11,3 \%$ \\
\hline
\end{tabular}

Here $40,5 \%$ of the students gave a correct definition; most of them gave this definition as a description. Around $30 \%$ of the students only gave a definition for a special case (equilateral triangle) and around $20 \%$ gave an incomplete definition. Here, most of the students tried to give the definition as a description; only in the case of the incomplete solutions there are more drawings than descriptions.

The results show that the students' ability to give a correct definition of a geometrical object is rather poor. Only $30-40 \%$ of the students in our sample were able to give a correct definition of the perpendicular bisector of a line or of an isosceles triangle. However, this fact does not necessarily mean that the students do not know what the perpendicular bisector of a line resp. an isosceles triangle is.

The incomplete answers are mostly drawings. In these cases most of the student do not see the necessity to give information about certain details in their drawing, e.g., that an angle in a drawing that looks like a right angle is really an angle of $90^{\circ}$ and so on. About $30 \%$ of the definitions of an isosceles triangle were definitions of an 
equilateral triangle. In these cases, we do not think that this is based on a restricted concept image, i.e., the equilateral triangle is an ideal example of an isosceles triangle (a prototype). In fact, most of the students gave a wrong definition because, in many cases, we got descriptive definitions like "A triangle with all sides of same length". We think that it is more likely that the students mixed up the two geometrical objects.

\subsection{Are students able to identify equivalent descriptions of simple geometrical objects?}

The number of correct answers for the six alternative descriptions of a square are presented in Table 3.

Table 3: Recognition of descriptions of a square

\begin{tabular}{|l|c|c|}
\hline $\begin{array}{l}\text { necessary and sufficient } \\
\text { conditions }\end{array}$ & Frequency & Percentage \\
\hline $\begin{array}{l}\text { 1) four sides of same length and } \\
\text { all angles of } 90^{\circ}\end{array}$ & 88 & $83,0 \%$ \\
\hline 2) four angles of $90^{\circ}$ & 48 & $45,3 \%$ \\
\hline $\begin{array}{l}\text { 3) three angles of } 90^{\circ} \text { and two } \\
\text { neighbouring sides of same length }\end{array}$ & 6 & $5,7 \%$ \\
\hline 4) all sides of same length & 34 & $32,1 \%$ \\
\hline 5) opposite sides are parallel & 63 & $59,4 \%$ \\
\hline $\begin{array}{l}\text { 6) four sides of same length and } \\
\text { one angle of } 90^{\circ}\end{array}$ & 19 & $17,1 \%$ \\
\hline
\end{tabular}

If we consider the alternative descriptions of a square (answers 1, 3 and 6), then we can see that $83 \%$ of the students know that quadrangles with four sides of same length and four angles of $90^{\circ}$ are squares. The fact, that four sides of same length and one right angle is also sufficient, is only recognised by $17,1 \%$ and the statement that three angles of $90^{\circ}$ and two neighbouring sides of same length are sufficient, is accepted by only $5,7 \%$. Conversely, more than half of the students think that a quadrangle with four right angles is already a square and more than two thirds believe that each equilateral quadrangle is a square. Reason for this may be the wrong understanding of necessary and sufficient conditions. The fact that, in general, a parallelogram is not a square is known by nearly $60 \%$ of the students. It is interesting to see that about two thirds of the students think that an equilateral quadrangle is already a square but only $17,1 \%$ gave the answer that an equilateral quadrangle with one angle of $90^{\circ}$ is a square.

If we consider the total number of correct answers for each student, we get the results in Table 4:

Table 4: Number of correct answers

\begin{tabular}{|c|c|c|}
\hline correct answers & Frequency & Percentage \\
\hline 0 & 0 & $0 \%$ \\
\hline 1 & 21 & $19,8 \%$ \\
\hline 2 & 35 & $33,0 \%$ \\
\hline 3 & 34 & $32,1 \%$ \\
\hline 4 & 15 & $14,2 \%$ \\
\hline 5 & 1 & $0,9 \%$ \\
\hline 6 & 0 & $0 \%$ \\
\hline
\end{tabular}

We can see that the students' ability to recognize equivalent descriptions of a square are rather poor. If we consider only the students who marked the correct answers, we see that $71,7 \%$ recognized one equivalent description, $13,2 \%$ two and only $2,8 \%$ (three students) recognized all three correct descriptions of a square among the six possible answers.

In the case of the equilateral triangle, we got the results presented in Table 5 .

Table 5: Recognition of descriptions of an equilateral triangle necessary and sufficient conditions Frequency Percentage

\begin{tabular}{|l|c|c|}
\hline 1) all angles of same degree & 82 & $77,4 \%$ \\
\hline $\begin{array}{l}\text { 2) two sides of same length and } \\
\text { one angle of } 60^{\circ}\end{array}$ & 28 & $26,4 \%$ \\
\hline $\begin{array}{l}\text { 3) two sides of same length and } \\
\text { two angles of same degree }\end{array}$ & 80 & $75,5 \%$ \\
\hline 4) two angles of $60^{\circ}$ & 30 & $28,3 \%$ \\
\hline $\begin{array}{l}\text { 5) three sides of same length and } \\
\text { one angle of } 90^{\circ}\end{array}$ & 78 & $73,6 \%$ \\
\hline $\begin{array}{l}\text { 6) two sides of same length and } \\
\text { the angle between is of } 60^{\circ}\end{array}$ & 20 & $18,9 \%$ \\
\hline
\end{tabular}

In this multiple-choice item, many students only marked the first answer. Consequently, they had correct solutions for the answers 1, 3 and 5 and wrong solutions for the answers 2, 4 and 6. However, we can see that more than three quarters of the students know that a triangle with three angles of same degree is equilateral and that more than one quarter of the students knows that a triangle with two sides of same length and one angle of $60^{\circ}$ resp. a triangle with two angles of $60^{\circ}$ is equilateral. As with the item with the square, we find the analogue phenomenom that 28 students know that two sides of same length and one angle of $60^{\circ}$ is a sufficient condition but only 20 students agree with this fact when the $60^{\circ}$ angle is between the two sides of same length.

If we take into account that students who made no mark have two correct answers and students who marked the first question have three correct answers, we can again say that the students' ability to recognise equivalent descriptions of an equilateral triangle are rather poor (cf. Table 6).

Table 6: Number of correct answers

\begin{tabular}{|c|c|c|}
\hline correct answers & Frequency & Percentage \\
\hline 0 & 0 & $0 \%$ \\
\hline 1 & 12 & $11,3 \%$ \\
\hline 2 & 17 & $16,0 \%$ \\
\hline 3 & 49 & $46,2 \%$ \\
\hline 4 & 17 & $16,0 \%$ \\
\hline 5 & 9 & $8,5 \%$ \\
\hline 6 & 2 & $1,9 \%$ \\
\hline
\end{tabular}

There were four correct descriptions of the equilateral triangle. Half of the students recognised only one of the correct answers, about $21 \%$ two, about $11 \%$ three and $5,7 \%$ recognised all four equivalent descriptions of a triangle.

\subsection{What kind of arguments convince students that a mathematical statement is true? Do students recognise correct and false proofs?}

In the first item, we asked why the statement about the sum of the angles in a triangle is true. The answers could be classified in different categories.

From Table 7 we see that the first two types of answers can be assigned to the category "based on a higher authority". Those students $(34,8 \%)$ argue that the statement is true, but there is no need for them to proof it (cf. the authoritarian proof scheme in Harel \& Sowder, 1998). Empirical arguments were preferred by $12,3 \%$ of the 
students, while 9,4\% gave reasons for the fact that the statement is true for special triangles (mostly equilateral triangles). About $43 \%$ of the students gave a senseless answer or no response.

Table 7: The sum of the angles in a triangle is $180^{\circ}$. Why is this statement true?

\begin{tabular}{|l|c|c|}
\hline & Frequency & Percentage \\
\hline "I learned it in such a way" & 9 & $8,4 \%$ \\
\hline $\begin{array}{l}\text { "That's the way it is", "It is } \\
\text { obvious" }\end{array}$ & 28 & $26,4 \%$ \\
\hline measure & 13 & $12,3 \%$ \\
\hline reason only for a special case & 10 & $9,4 \%$ \\
\hline senseless / no response & 46 & $43,4 \%$ \\
\hline
\end{tabular}

These results indicate that only for less than a quarter of the students there is a need to give reasons that the statement about the sum of the interior angles in a triangle is true. However, half of these students prefer empirical reasons.

In the second item we gave the "proofs" of Ingo, Meike and Beate for the statement about vertical angles to the students. They were to decide which of this solutions they like most and which is correct.

Table 8: Which proof do you like most? Which is correct?

\begin{tabular}{|l|c|c|c|c|}
\hline & \multicolumn{2}{|c|}{ like most } & \multicolumn{2}{c|}{ is correct } \\
\hline & Frequency & Percentage & Frequency & Percentage \\
\hline $\begin{array}{l}\text { Ingo / } \\
\text { empirical }\end{array}$ & 55 & $51,9 \%$ & 41 & $38,7 \%$ \\
\hline $\begin{array}{l}\text { Meike / } \\
\text { correct }\end{array}$ & 8 & $7,5 \%$ & 8 & $7,5 \%$ \\
\hline $\begin{array}{l}\text { Beate / } \\
\text { special case }\end{array}$ & 36 & $34,0 \%$ & 22 & $20,8 \%$ \\
\hline $\begin{array}{l}\text { Ingo \& } \\
\text { Beate }\end{array}$ & 3 & $2,8 \%$ & 9 & $8,5 \%$ \\
\hline $\begin{array}{l}\text { Ingo \& } \\
\text { Meike }\end{array}$ & 2 & $1,9 \%$ & 2 & $1,9 \%$ \\
\hline $\begin{array}{l}\text { Meike \& } \\
\text { Beate }\end{array}$ & 0 & $0,0 \%$ & 1 & $0,9 \%$ \\
\hline all & 1 & $0,9 \%$ & 11 & $10,4 \%$ \\
\hline $\begin{array}{l}\text { no } \\
\text { response }\end{array}$ & 1 & $0,9 \%$ & 12 & $11,3 \%$ \\
\hline
\end{tabular}

The results in Table 8 indicate that more than half of the grade 8 students like empirical arguments most $(51,9$ $\%)$. If we add the number of responses which choose Ingo, then we have 61 students $(57,5 \%)$ which, on the one hand, prefer empirical arguments and, on the other hand, think that an empirical reasoning is correct. Beate's solution, which includes the special case of $45^{\circ}$ angles and the use of a non-existing statement "proposition about squares" without further explanation, is correct for 40,6 $\%$ of the students and is the favourite "proof" for more than a third of the students $(37,7 \%)$. The correct solution of Meike is recognised as correct by $20,7 \%$ of the students, but only $10,3 \%$ like this correct solution most.

These results correspond with other empirical findings stating that many students in grade 8 accept empirical arguments (e.g., de Villers, 1992; Hoyles \& Küchemann, 2001; Reiss \& Thomas, 2001). Moreover, there are deficits in the understanding regarding reasoning and proof in mathematics, since for most of the students there seems to be no need to give reasons for the validity of a statement.
3.4 Do students know that, in general, the converse of a logical implication is not true?

Here we gave two statements (one mathematical and one of "daily life") together with the converses of these statements to the students and asked, whether these converse statement are true. In many case the students gave reasons for their answer though this was not required. From these reasons, we could see that some students understood the daily life situation ("If it rains, then the street becomes wet" and "If the street is wet, then it rains") under a temporal aspect and argued with the temporal order ("If the rain stops, then the street will be wet for some time, though it may be sunny then.").

Results for the daily life situation are given in Table 9.

Table 9: Converse of an implication (daily life)

\begin{tabular}{|l|c|c|}
\hline & Frequency & Percentage \\
\hline correct with counterexample & 49 & $46,2 \%$ \\
\hline correct with a temporal aspect & 16 & $15,1 \%$ \\
\hline correct without reasons & 7 & $6,6 \%$ \\
\hline false & 21 & $19,8 \%$ \\
\hline no response & 13 & $12,3 \%$ \\
\hline
\end{tabular}

Around $68 \%$ of the students gave the correct response that the converse of the implication "If it rains, then the street becomes wet" is not true. Thereby, the predominant proportion argues with a counterexample, e.g., "The street could be sprayed, so it is wet without rain."

The second item was a mathematical problem with simple geometrical objects: "If a quadrangle is a rectangle, then the opposite sides are parallel. Consequently, we also have If the opposite sides of a quadrangle are parallel, then it is a rectangle. Is this true?". The students' answers are presented in Table 10.

Table 10: Converse of an implication (mathematics)

\begin{tabular}{|l|c|c|}
\hline & Frequency & Percentage \\
\hline correct with reasons & 2 & $1,9 \%$ \\
\hline correct without reasons & 8 & $7,5 \%$ \\
\hline correct with false reasons & 29 & $27,4 \%$ \\
\hline false & 25 & $23,8 \%$ \\
\hline no response & 42 & $39,6 \%$ \\
\hline
\end{tabular}

About $37 \%$ gave a right answer, whereby many students $(27,4 \%)$ gave wrong reasons for their response. In most of these cases, they tried to give a counterexample but mixed up the concepts of quadrangle, rectangle and square. In particular, we noticed that many students do not distinguish between the words (and concepts?) of squares and quadrangles. Remarkable is also the fact that nearly $40 \%$ of the students gave no response to this item.

Comparing the results for these two items, we can observe that most of the students know that, in general, the converse of a logical implication is not true. However, it is remarkable that about two thirds of the students recognise this fact in a daily situation and only about $37 \%$ in a mathematical situation.

\subsection{Are students familiar with the principle of counter- examples?}

In order to answer this question we presented two items to the students, each of them with one mathematical statement. The students were asked to show that these statements are non-correct.

The first item dealt with basic geometrical object: 
"Klaus considers squares and rectangles. He says: 'In each quadrangle is each angle $90^{\circ}$.' Karin says:' This is not true'. How can you show, that Karin is right?'.

Table 11: Using counterexamples

\begin{tabular}{|l|c|c|}
\hline & Frequency & Percentage \\
\hline correct (counterexample) & 65 & $61,3 \%$ \\
\hline correct (explanation) & 3 & $2,8 \%$ \\
\hline false & 22 & $20,7 \%$ \\
\hline no response & 16 & $15,1 \%$ \\
\hline
\end{tabular}

More than $60 \%$ of the students gave a correct answers using a counterexample (cf. Table 11). Three students explained in other ways that the statement is not correct.

The second item dealt with circles: "Klaus say: 'For each triangle $\mathrm{ABC}$ I can find a circle through the points $\mathrm{A}, \mathrm{B}, \mathrm{C}$ and for each quadrangle $\mathrm{ABCD}$ I can find a circle through A, B, C, D.' Beate laughs and says: 'I can refute one of your statements'. Describe how Beate can do this."

For this item we got a broad range of answers. Many students did not present some kind of no solution but answered something like "We did not learn this till now" Others tried to treat both statements (for the triangles and for the quadrangles), because they did not know which statement was right and which was wrong. Some of them gave a correct answer for the quadrangle but a wrong one for the triangle. Altogether, 58,5\% of the students gave no response and $21,7 \%$ gave a completely false answer. About $10 \%$ gave an answer that was correct and another $10 \%$ gave a partly correct answer (i.e., correct for quadrangle, not correct for triangle). Since we are interested in the principle of counterexamples, we considered the students which used counterexamples. Here we found 10 students $(9,4 \%)$ using correct counterexamples for the quadrangle, but seven of them gave an answer for the triangle that was wrong.

The results for these two items indicate that the most of students are familiar with the principle of counterexamples. Already in section 3.4 we saw that students used counterexamples to show that the converse of a logical implication is not true. The comparatively weak results for the second item (circles through the points of a triangle, quadrangle) are related to the fact that many students refused to give an answer for this item. They argued that the question of circles through the points of a triangle/quadrangle was not treated in the mathematics classroom yet.

\section{Summary and discussion}

Our investigation of students' declarative and methodological knowledge was motivated by the recent empirical identification of aspects of geometrical competence resp. prerequisites for geometrical proofs in geometry classroom. As described at the beginning, several studies identified in particular declarative knowledge, methodological knowledge, metacognition and spatial abilities as these aspects resp. prerequisites. According to these results, we picked out several geometrical concepts or principles related to the declarative and methodological knowledge and investigated 106 grade 8 students from a German Realschule. These concepts or principles are definitions, equivalent descriptions, the understanding of proof, the understanding of implications and the principle of counterexamples.

If we consider the declarative knowledge, i.e., the knowledge of geometrical concepts and their properties, we see that students are quite unfamiliar with defining geometrical objects. About $30-40 \%$ of the students in our sample were able to give a definition of the perpendicular bisector of a line or of an isosceles triangle. In the case of equivalent descriptions of a square, only $16 \%$ of the students recognise more than one of the three offered possibilities; in the case of the equilateral triangle, $38 \%$ recognise more than one of four correct descriptions. The fact that many students think that four congruent angles or four congruent sides in a quadrangle are sufficient for the definition of a square is noticeable. A reason for this may be the wrong understanding of necessary and sufficient conditions. Furthermore, the results for the definition items indicate that for students using drawings to define geometrical objects do not see the necessity to point out right angles and so on explicitly.

For the investigated aspects of the methodological knowledge, there is a certain variety of the results from our sample. For less than a quarter of the students there is a need to give reasons that a mathematical statement is true. Many students accept empirical arguments for proving a statement. It is doubtful that students with these deficits can get a deeper insight into geometrical reasoning and proof.

The fact that a logical implication is, in general, not reversible is recognised from many students in a daily life situation. However, here we have a big difference between daily life situations and mathematical situations. It seems that it is much more difficult for the students to recognise that an implication is, in general, not reversible if a mathematical situation is considered. Since the number of false responses for both items are nearly equal but the number of no responds differs strongly (12,3\% to $39,6 \%$ ), aspects of mathematical competence and motivational aspects may play a role. The fact that in both items many students used counterexamples in the correct responses shows that they are familiar with the principle of counterexamples (see below). It is remarkable that in the mathematical item many students mixed up the concepts of rectangle, square and quadrangle. As mentioned above, this may be based on deficits in the understanding of necessary and sufficient conditions in a definition or description of an geometrical object.

The principle of counterexamples is known to most of the students and they are able to use it. For the item with the quadrangle nearly two thirds of the responses were correct and nearly all students used a counterexample in their answer. The item with the circle through the points of a triangle resp. quadrangle was much more difficult. Here the students did not know which counterexample they had to search for. Consequently, there were more wrong responses.

As mentioned in Section 1.3 the considered five mathematical concepts and principles are rarely taught or discussed explicitly in the mathematics classroom. The results of our investigation show certain deficits in students' declarative and methodological knowledge; most of these deficits can be overcome by different techniques 
of instruction in mathematics classroom. For example, to prevent one of the basic problems, the restricted concept image of geometrical objects in student minds, an explicit and repeated discussion of definitions and equivalent descriptions of geometrical objects joint with a big variety of examples will be helpful. However, the portion of students who gave no response or a senseless response (up to $40 \%$ for some items) may not be explained only by deficits in the declarative and methodological knowledge in mathematics. According to the recently published results of the PISA-study for Germany (Deutsches PisaKonsortium, 2001) we assume that other reasons like reading literacy play a role.

\section{References}

Balacheff, N. (1988). Aspects of Proof in Pupils Practice of School Mathematics. In D. Pimm (Ed.), Mathematics, Teachers, and Children, (216-235). London: Hodder and Stoughton.

Balacheff, N. (1991). Treatment of refutations: Aspects of the complexity of a constructivist approach to mathematics learning. In E. von Glasersfeld, (ed.), Radical constructivism in mathematics education, $(89$ - 110). Dordrecht: Kluwer.

Baumert, J., Bos, W. \& Lehmann, R. (2000). TIMSS/III - Dritte Internationale Mathematik- und Naturwissenschaftsstudie. Mathematische und naturwissenschaftliche Bildung am Ende der Schullaufbahn. Mathematische und physikalische Kompetenzen am Ende der gymnasialen Oberstufe (Bd. 2). Opladen: Leske + Budrich.

Beaton, A. E.; Mullis, I.V.S.; Martin, M. O.; Gonzalez, E. J.; Kelly, D. L.; Smith, T. A. (1996). Mathematics achievement in the middle school years. IEA's third International Mathematics and Science Study (TIMSS). Chestnut Hill, MA: Center for the Study of Testing, Evaluation and Educational Policy.

Boero, P. (1999). Argumentation and mathematical proof: A complex, productive, unavoidable relationship in mathematics and mathematics education. International Newsletter on the Teaching and Learning of Mathematical Proof, 7/8.

Burger, W. F. \& Shaughnessy, J. M. (1985) Spadework Prior to Deduction in Geometry. Mathematics Teacher 78 (6), 419 428.

Burger, W. F. \& Shaughnessy, J. M. (1986) Characterising the van Hiele levels of development in geometry. Journal of Research in Mathematics Education 17 (1), 31 - 48.

Clemens, D. H. \& Battista, M. T. (1992). Geometry and spatial reasoning. In: D. A. Grouws (ed.) Handbook of research on mathematics teaching and learning, (420 - 464).New York: Macmillian.

Deutsches Pisa-Konsortium (Hrsg.). (2001). PISA 2000: Basiskompetenzen von Schülerinnen und Schülern im internationalen Vergleich. Opladen: Leske + Budrich.

de Villiers, M. (1992). Children's Acceptance of Theorems in Geometry. Poster presentation at the $16^{\text {th }}$ Conference of the International Group for the Psychology of Mathematics Education (PME 16), University of New Hampshire, USA.

Flavell, J. H. (1977). Cognitive Development. Englewood Cliffs, N.J., Pretince Hall.

Greeno, J. G. (1980). Some examples of cognitive task analysis with instructional implications. In: R. E. Snow, P. Frederico, W. E. Montague (Eds.) Aptitude, learning and instruction, Vol. 2, (1 - 21). Hillsdale, NJ: Erlbaum.

Hanna, G. (1983). Rigorous proof in mathematics education. Toronto, Ontario: Ontario Institute for Studies in Education.

Hanna, G. (1997). The ongoing value of proof. Journal für Mathematikdidaktik, 18, 171-185.
Hanna, G. \& Jahnke, H. N. (1996). Chapter 23: Proof and Proving. In: Bishop, A. J.; Clements, K.; Keitel, C.; Kilpatrick, J.; Laborde, C. (eds.) International Handbook on Mathematics Education. Vol. 4, Part 2, (877 - 908). Dordrecht: Kluwer.

Harel, G. \& Sowder, L. (1998). Students' Proof Schemes: Results from Exploratory Studies. In A.H. Schoenfeld, J. Kaput, \& E. Dubinsky (Eds.), Research in Collegiate Mathematics Education, (234 - 283). Providence, RI: American Mathematical Society.

Healy, L \& Hoyles, C. (1998). Justifying and proving in school mathematics. Technical Report on the Nationwide Survey. Mathematical Science. London: Institute of Education, University of London.

Hershkowitz, R. \& Vinner, S. (1980). Concept Images and Common Cognitive Paths in the Development of Some Simple Geometrical Concepts. In: R. Karplus (ed.) Proceedings of the $4^{\text {th }}$ Conference of the International Group for the Psychology of Mathematics Education, (177 - 184). Berkley: University of California, Lawrence Hall of Science.

Hershkowitz, R. \& Vinner, S. (1982). Basic geometric concepts - definitions and images. In: Vermandel, A. Wilrijk, Proceedings of the $6^{\text {th }}$ Conference of the International Group for the Psychology of Mathematics Education, (18 - 23). Universitaire Instelling Antwerpen, Antwerp (Belgium).

Hoyles, C. \& Küchemann, D. (2001). Identifying Differences in Students' Evaluation of Mathematical Reasons. Paper presented at the British Congress of Mathematics Education, March 2001, Manchester.

Koedinger (1998). Conjecturing and argumentation in highschool geometry students. In R. Lehrer \& D. Chazan (Eds.). Designing learning environments for developing understanding of geometry and space. Mahwah, NJ: Erlbaum.

Koedinger, K. R. \& Anderson, J. R. (1990). Abstract planning and perceptual chunks: Elements of expertise in geometry. Cognitive Science, 14, 511 - 550.

Kuhn, D. (1989). Children and adults as intuitive scientists. Psychological Review, 96, 674-689.

Lehrer, R. \& Chazan, D. (Eds.) (1998). Designing Learning Enviroments for Developing Understanding of Geometry. Mahwah, NJ: Lawrence Erlbaum.

Moore, R. C. (1994). Making transition to formal proof. Educational Studies in Mathematics, 27, 249 - 266.

National Council of Teachers of Mathematics (Ed.) (2000). Principles and Standards for School Mathematics. Reston, VA: NCTM.

Reiss, K., Klieme, E. \& Heinze, A. (2001). Prerequisites for the understanding of proofs in the geometry classroom. In M. van den Heuvel-Panhuizen (Ed.), Proceedings of the 25th Conference of the International Group for the Psychology of Mathematics Education. Vol. 4, (97 - 104). Utrecht (The Netherlands): Utrecht University.

Reiss, K. \& Thomas, J. (2001). Wissenschaftliches Denken beim Beweisen in der Geometrie. Ergebnisse einer Studie mit Schülerinnen und Schülern der gymnasialen Oberstufe. Mathematica didactica 23 (1), 96 - 112.

Reiss, K. \& Hellmich, F. (submitted). Bedingungen für das Argumentieren, Begründen und Beweisen in der Sekundarstufe. Zeitschrift für Pädagogik.

Senk, S. (1985). How Well Do Students Write Geometry Proofs? Mathematics Teacher 78 (6), 448 - 456.

Vinner, S. (1991). The Role of Definitions in Teaching and Learning of Mathematics. In: D. Tall (ed.) Advanced Mathematical Thinking, $(65$ - 81). Dordrecht: Kluwer.

Wilson (1986). The role of negative instances in geometric feature identification task. Journal of Research in Mathematics Education 17, 130 - 139.

Wilson (1990). Inconsistent ideas related to definitions and 
examples. Focus on Learning Problems of Mathematics 12 (3/4), $31-47$.

\section{Authors}

Heinze, Aiso, Dr., Fachbereich Mathematik, Carl von Ossietzky-Universität Oldenburg, 26111 Oldenburg.

Email: heinze@mathematik.uni-oldenburg.de

Kwak, Jee Yi., Fachbereich Mathematik, Carl von Ossietzky-

Universität Oldenburg, 26111 Oldenburg.

Email: kwak@mathematik.uni-oldenburg.de 